\section{Engendering International Health: The Challenge of Equity}

\author{
Edited by Gita Sen, Asha George \\ \& Piroska Östlin \\ The MIT Press \\ $467 p p, \$ 24.95,2002$
}

\section{REVIEWED BY M. OMAR RAHMAN \\ Department of Population and International \\ Health, Harvard School of Public Health \\ Boston, Massachusetts, USA}

Engendering International Health: The Challenge of Equity is a volume of essays that focuses on gender issues in health. A primary goal of the book is to convince the reader that researchers and policy makers have not adequately addressed gender issues and that this lack of attention has had dire consequences for the efficacy and equity of health programs and policies. This premise, while not controversial, is one that I feel is worth re-iterating. The various essays in this volume (some better than others) describe how research and policy have not done justice to the different needs and challenges of women's health vis-àvis that of men, tending instead to view health problems with an uncritical 'onesize-fits-all' approach.

The issue of whether women are, in fact, in worse health than men, and what society should do about it, is somewhat more complex than one might think from a superficial reading of this book. As some of the authors point out, this topic has been bedeviled by a lack of specific data. It is well established, for example, that women in most societies (except in South Asia) live longer on average than their male counterparts. The higher morbidity of women as compared with men, however, is still debated in some quarters. In any case, how one should interpret and respond to gender disparities remains a complex enterprise.

This book has some interesting observations on gender equity versus gender equality, with the latter being viewed as overly simplistic and formulaic. The authors seem to favor a notion of gender equity, advocating societal intervention only when biological advantages are minimized or negated. This would be the case in South Asia, for example, where the biological advantages of longer survival by women have been compromised by social ne-

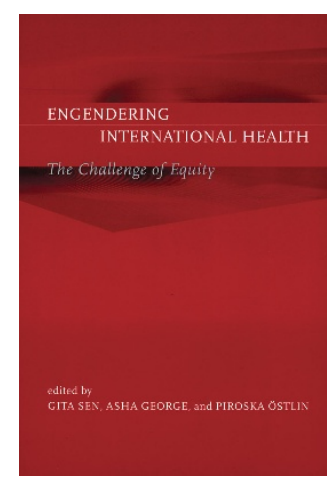

plicated subject. One cannot cleanly dissociate gender from other social determinants such as income, wealth, social role, class, race and ethnicity. Is gender just a holding ground for these often invisible and unmeasurable socio-demographic forces? In some recent, more nuanced analyses of gender differences in health, controls for these other 'confounding factors' are often presented with significant unexplained residuals being attributed to gender. The authors argue that this is prima facie evidence of gender being the appropriate level for analyzing health differences and intervention. Others might counter that these so-called 'gender effects' reflect our lack of appropriate measures for these other factors. This is not merely an arcane debate; it has real implications for how policy should be oriented.

Some of the best chapters in this book have to do glect. This is somewhat of a slippery slope, as some might argue that social intervention should provide both men and women with equal opportunities for good health, despite biological or behavioral predisposition. From this perspective, one could then argue that societal resources should be allocated to ensure that men do not engage in health-negating behaviors such as excessive substance abuse (drinking or smoking) and other risky endeavors (driving rashly or using handguns). These arguments lead to some thorny philosophical pitfalls.

The interaction between gender and other social stratifiers is an equally com- with bias, whether conscious or not, in algorithms for deciding health priorities and interventions. Although gender-related examples are addressed, one can easily gather from these analyses that a variety of vulnerable groups are ignored or neglected in many distributive paradigms.

Equity is indeed a difficult concept to define and agree on, the problem being that different people see it differently. On the whole, I enjoyed reading this book. Its insights into the topic of gender differences in health provide both the uninitiated and the veteran with thought provoking ideas and assertions. 